\title{
Ratings of voice attractiveness predict sexual behavior and body configuration
}

\author{
Susan M. Hughes ${ }^{1}$, Franco Dispenza, Gordon G. Gallup Jr.* \\ Department of Psychology, State University of New York at Albany, Albany, NY 12222, United States
}

Received 22 March 2004; received in revised form 10 May 2004

\begin{abstract}
We investigated the relationship between ratings of voice attractiveness and sexually dimorphic differences in shoulder-to-hip ratios (SHR) and waist-to-hip ratios (WHR), as well as different features of sexual behavior. Opposite-sex voice attractiveness ratings were positively correlated with SHR in males and negatively correlated with WHR in females. For both sexes, ratings of opposite-sex voice attractiveness also predicted reported age of first sexual intercourse, number of sexual partners, number of extra-pair copulation (EPC) partners, and number of partners that they had intercourse with that were involved in another relationship (i.e., were themselves chosen as an EPC partner). Coupled with previous findings showing a relationship between voice attractiveness and bilateral symmetry, these results provide additional evidence that the sound of a person's voice may serve as an important multidimensional fitness indicator.
\end{abstract}

(C) 2004 Elsevier Inc. All rights reserved.

Keywords: Voice attractiveness; Shoulder-to-hip ratio; Waist-to-hip ratio; Sexual behavior; Mate selection; Nocturnal communication

* Corresponding author. Tel.: +1 518442 4852; fax: +1 5184424867.

E-mail address: gallup@albany.edu (G.G. Gallup Jr.).

${ }^{1}$ Now at Vassar College, Poughkeepsie, NY 12604. 


\section{Introduction}

There is growing evidence that the sound of a person's voice may convey important information. Studies have shown that listeners who hear voice samples can infer the speaker's socioeconomic status (Ellis, 1967; Harms, 1963), personality traits (Allport \& Cantril, 1934; Zuckerman \& Driver, 1989), and emotional and mental state attributes related to deception (Ekman, Friesan, \& Scherer, 1976; Streeter, Krauss, Geller, Olson, \& Apple, 1977). Listeners exposed to voice samples are also capable of estimating the age, height, and weight of speakers with the same degree of accuracy achieved by examining photographs (Krauss, Freyberg, \& Morsella, 2002; Lass \& Colt, 1980; Lass \& Davis, 1976). Independent raters are also capable of matching a speaker's voice with the person's photograph over $75 \%$ of the time (Krauss et al., 2002). Hughes, Harrison, and Gallup (2002) found that individuals with symmetrical morphological traits were rated as having more attractive voices, and as deviations from bilateral symmetry increased, ratings of voice attractiveness decreased.

Vocal development is influenced and modified by activational sex hormones during adolescence. Estrogen and progesterone shape the mature female voice, while testosterone modifies the male voice (Abitbol, Abitbol, \& Abitbol, 1999) The same hormones that affect voice have also been implicated in the development of sex-specific body configuration features. For instance, waist-to-hip ratios (WHR) in females become more accentuated during puberty, and WHR is an indicator of a female's hormonal profile (increased estrogen) and reproductive status (Singh, 1993). Similarly, during puberty, the male's shoulders broaden, increasing his shoulder-to-hip ratio (SHR). Broad shoulders and narrow hips appear to be shaped by testosterone (Kasperk et al., 1997). Because both voice and WHR/SHR are affected by sex hormones, we examined whether ratings of voice attractiveness were related to variation in SHR and WHR.

WHR and SHR not only influence judgments of attractiveness (Djkstra \& Buunk, 2001; Singh, 1993), but also, variation in these traits predicts different aspects of sexual behavior in both males and females (Hughes \& Gallup, 2003). Women with low WHR (smaller waist compared with the hips) are rated as being more attractive (Beck, Ward-Hull, \& McClear, 1976; Singh, 1993), report having sex at an earlier age, and report having more sex partners (Hughes \& Gallup, 2003; Mikach \& Bailey, 1999). Men with high SHR (larger shoulders and smaller hips) are likewise judged to be more attractive (Dijkstra \& Buunk, 2001) and are also more sexually experienced (Hughes \& Gallup, 2003). Therefore, we also examined the relationship between ratings of voice attractiveness and different features of sexual behavior.

\section{Methods}

\subsection{Participants}

A total of 149 undergraduate students (77 females and 72 males) from the State University of New York at Albany participated in this study, which was approved by the campus 
Institutional Review Board. Mean age was 20.9 years (S.D. =4.8) with a range of 18-50. Participants were not informed of the purpose of the study.

\subsection{Voice stimuli}

Voices were individually recorded onto computer software (Microsoft Sound Recorder) in a small, quiet room as participants counted from 1 to 10 to obtain vocal samples that were neutral and of comparable content. Participants were given an example of counting from 1 to 10 at the rate of approximately one numeral per second, and voice samples were recorded on the first trial, unless an error occurred in the recording. A unidirectional microphone (Andrea $\mathrm{NC}-8$ ) positioned approximately 1 in. from the participant's mouth was used to record voices. The participants who were chronic smokers (smoked more than a pack of cigarettes a week), indicated that English was not their first language or had obvious accents, had a cold or illness that may have affected the way they normally spoke (i.e., severe congestion), had ever broken their nose, had surgery on their throat or larynx that affected their speech, had a hearing impairment, or had auditory surgery were excluded from the analyses (yielding a final sample of 76 females and 70 males).

The participants in this study also served as independent raters for voices that were recorded from other participants. Raters were not given any information about the participants whose voices had been recorded, nor were raters allowed to see or identify the individuals whose voices they were rating. The raters scored the anonymous voice recordings using a five-point scale $(1=$ very unattractive, $2=$ somewhat unattractive, $3=$ average, $4=$ somewhat attractive, $5=$ very attractive). There was a total of $12 \pm 2$ raters for each voice, and all of the voices were rated by approximately an equal number of male and female raters $(6 \pm 2)$. Each voice sample was presented to the rater once, unless the rater asked to hear the voice a second time. Raters were asked if they recognized any of the voices and were told not to rate voices of individuals they thought they knew. None of the raters indicated recognizing any of the voice recordings. The interrater reliability for voice attractiveness ratings was reasonably high (Cronbach alpha, $r=.651, p<.01$; Kendall coefficient of concordance, $W=0.315, p<.01)$.

\subsection{Body measurements}

The circumference of the shoulders, waist, and hips was measured to the nearest $0.5 \mathrm{~cm}$, by an investigator who had not seen the questionnaire responses, using an anthropometric fiberglass body measuring tape. Waist circumference was measured at the level of the umbilicus as the smallest girth between the rib cage and iliac crest. Hip circumference was defined as the greatest distance around the hips and buttocks, a measure of the largest girth between the waist and thigh. Shoulder circumference was taken at the greatest width of the shoulders while the participant stood with arms relaxed to the sides. None of the participants indicated being pregnant or reported having broken bones associated with the traits being measured. Each trait was measured twice by the same investigator, and remeasurement reliability was high: shoulders, $r=.996$; waist, $r=.998$; and hips, $r=.995$. 
Because WHR can be affected by body mass, the relationship between body mass and ratings of voice attractiveness was also examined. To calculate body mass index (BMI), using the formula $\mathrm{kg} / \mathrm{m}^{2}$ (Tovée, Reinhardt, Emery, \& Cornelissen, 1998), the participants were also measured for height and weight.

\subsection{Sexual behavior measures}

About half the participants (34 females and 43 males) also completed an anonymous questionnaire in private concerning their sexual history. The questionnaire asked the age when the participants first masturbated (as an index of the onset of sexual behavior), age of first sexual intercourse, number of sexual partners, number of extra-pair copulation (EPC) partners, and number of people they had intercourse with whom they knew were involved in another relationship (i.e., were themselves chosen as an EPC partner). One participant reported being homosexual, three had children, and four were married; but each of these subgroups was too small to consider for separate analyses.

\section{Results}

\subsection{Voice and morphology}

Male SHRs $(M=1.15 \pm 0.076$, range 1.01-1.47) exceeded female SHRs $(M=1.04 \pm 0.075$, range $0.84-1.19 ; t=8.69, p<.01)$. Male WHRs $(M=0.86$, S.D. $=0.75$, range 0.74 to 1.18$)$ also exceeded female WHRs $(M=0.78$, S.D. $=0.61$, range 0.64 to $0.97 ; t=6.81, p<.01)$. Likewise, male BMI $(M=25.35 \pm 4.06)$ was higher than female BMI $(M=23.87 \pm 4.24$; $t=2.15, p<.05)$. Correlations between opposite- and same-sex ratings of voice attractiveness and morphological features are presented in Tables 1 and 2. Opposite-sex ratings of voice attractiveness were positively correlated with SHR $(r=.503 p<.01)$ in males and negatively correlated with WHR $(r=-.376, p<.01)$ in females. There was no relationship between voice attractiveness and BMI in either males or females. Controlling for the other morphological features had little or no effect on these outcomes. The partial correlation between voice attractiveness and SHR in males was $r=.467(p<.01)$, whereas for females, the partial correlation between voice attractiveness and WHR was $r=-.375(p<.01)$. Partial correlations between voice attractiveness ratings and BMI when controlling for SHR, WHR, as well as age were nonsignificant in both males and females.

\subsection{Morphology and sexual behavior}

Descriptive statistics for self-reported measures of sexual behavior are presented in Table 3. As shown in Table 1, SHR for males was negatively correlated with reported age of first sexual intercourse and positively correlated with reported number of sex partners, number of EPC partners, and number of people they had intercourse with who were involved in another relationship. For females, WHR was positively correlated with reported age of first sexual 
Table 1

Pearson correlations (sample size) between voice attractiveness ratings, WHR, SHR, BMI, and various measures of sexual behavior in males

\begin{tabular}{|c|c|c|c|c|c|c|c|c|c|}
\hline Males & $\begin{array}{l}\text { Opposite-sex } \\
\text { ratings of voice } \\
\text { attractiveness }\end{array}$ & $\begin{array}{l}\text { Same-sex } \\
\text { ratings of voice } \\
\text { attractiveness }\end{array}$ & WHR & SHR & BMI & $\begin{array}{l}\text { Age of first } \\
\text { masturbation }\end{array}$ & $\begin{array}{l}\text { Age of } \\
\text { first sex }\end{array}$ & $\begin{array}{l}\text { Number of } \\
\text { sex partners }\end{array}$ & $\begin{array}{l}\text { Number of } \\
\text { times being } \\
\text { an EPC } \\
\text { partner }\end{array}$ \\
\hline WHR & $.150(70)$ & $.174(70)$ & & & & & & & \\
\hline SHR & $.503 * *(70)$ & $.375^{* *}(70)$ & $.302 *(70)$ & & & & & & \\
\hline BMI & $.024(70)$ & $-.093(70)$ & $.575^{* *}(70)$ & $.118(70)$ & & & & & \\
\hline $\begin{array}{l}\text { Age of first } \\
\text { masturbation }\end{array}$ & $-.101(36)$ & $-.219(36)$ & $.071(36)$ & $-.233(36)$ & $.105(36)$ & & & & \\
\hline Age of first sex & $-.410 *(34)$ & $-.273(34)$ & $.159(34)$ & $-.419 *(34)$ & $-.061(34)$ & $.312(30)$ & & & \\
\hline $\begin{array}{l}\text { Number of sex } \\
\text { partners }\end{array}$ & $.359 *(43)$ & $.327 *(43)$ & $.187(43)$ & $.533 * *(43)$ & $.161(43)$ & $-.357 *(36)$ & $-.442 * *(34)$ & & \\
\hline $\begin{array}{l}\text { Number of EPC } \\
\text { partners }\end{array}$ & $.400 * *(43)$ & $.356^{*}(43)$ & $.150(43)$ & $.491 * *(43)$ & $.132(43)$ & $-.289(36)$ & $-.373 *(34)$ & $.781 * *(43)$ & \\
\hline $\begin{array}{l}\text { Number of times } \\
\text { being an EPC } \\
\text { partner }\end{array}$ & $.317 *(43)$ & $.261(43)$ & $.181(43)$ & $.449 * *(43)$ & $.036(43)$ & $-.143(36)$ & $-.381 *(34)$ & $.548 * *(43)$ & $.551 * *(43)$ \\
\hline
\end{tabular}


Table 2

Pearson correlations (sample size) between voice attractiveness ratings, WHR, SHR, BMI, and various measures of sexual behavior in females

\begin{tabular}{|c|c|c|c|c|c|c|c|c|c|}
\hline Females & $\begin{array}{l}\text { Opposite-sex } \\
\text { ratings of voice } \\
\text { attractiveness }\end{array}$ & $\begin{array}{l}\text { Same-sex } \\
\text { ratings of voice } \\
\text { attractiveness }\end{array}$ & WHR & SHR & BMI & $\begin{array}{l}\text { Age of first } \\
\text { masturbation }\end{array}$ & $\begin{array}{l}\text { Age of } \\
\text { first sex }\end{array}$ & $\begin{array}{l}\text { Number of } \\
\text { sex partners }\end{array}$ & $\begin{array}{l}\text { Number of } \\
\text { times being } \\
\text { an EPC } \\
\text { partner }\end{array}$ \\
\hline WHR & $-.376^{* *}(76)$ & $-.021(76)$ & & & & & & & \\
\hline SHR & $-.107(76)$ & $.192(76)$ & $.189(76)$ & & & & & & \\
\hline BMI & $.000(76)$ & $-.011(76)$ & $.363 * *(76)$ & $-.514 * *(76)$ & & & & & \\
\hline $\begin{array}{l}\text { Age of first } \\
\text { masturbation }\end{array}$ & .043 (17) & $-.121(17)$ & $.280(17)$ & $-.182(17)$ & $.265(17)$ & & & & \\
\hline Age of first sex & $-.397 *(28)$ & $-.171(28)$ & $.376 *(28)$ & $-.345(28)$ & $.575^{* *}(28)$ & $.264(14)$ & & & \\
\hline $\begin{array}{l}\text { Number of sex } \\
\text { partners }\end{array}$ & $.491 * *(34)$ & $.409 *(34)$ & $-.349^{*}(34)$ & $-.046(34)$ & $-.107(34)$ & $-.216(17)$ & $-.376 *(28)$ & & \\
\hline $\begin{array}{l}\text { Number of EPC } \\
\text { partners }\end{array}$ & $.374 *(34)$ & $.295(34)$ & $-.347 *(34)$ & -.019 (34) & $-.122(34)$ & $.022(17)$ & $-.242(28)$ & $.490 * *(34)$ & \\
\hline $\begin{array}{l}\text { Number of times } \\
\text { being an EPC } \\
\text { partner }\end{array}$ & $.353 *(34)$ & $.401 *(34)$ & $-.339 *(34)$ & $-.023(34)$ & $-.134(34)$ & -.025 (17) & $-.117(28)$ & $.566^{* *}(34)$ & $.612 * *(34)$ \\
\hline
\end{tabular}


Table 3

The mean and standard deviation for the sexual behavior measures in males and females

\begin{tabular}{|c|c|c|c|c|c|c|}
\hline & \multicolumn{3}{|c|}{ Males } & \multicolumn{3}{|c|}{$\underline{\text { Females }}$} \\
\hline & $n$ & Mean & S.D. & $n$ & Mean & S.D \\
\hline Age of first masturbation & 36 & 13.16 & 1.78 & 17 & 13.82 & 2.98 \\
\hline Age of first sex & 34 & 16.94 & 1.37 & 28 & 16.82 & 1.68 \\
\hline Number of sex partners & 43 & 4.44 & 6.61 & 34 & 2.94 & 2.95 \\
\hline Number of EPC partners & 43 & 0.53 & 1.22 & 34 & 0.23 & 0.55 \\
\hline Number of times being an EPC partner & 43 & 0.19 & 0.045 & 34 & 0.21 & 0.48 \\
\hline
\end{tabular}

intercourse, and negatively correlated with the number of reported sex partners, EPC partners, and partners they had intercourse with that were involved in another relationship (see Table 2). Whereas BMI was not correlated with any of the measures of sexual behavior in males, BMI was correlated with age of first sexual intercourse for females $(r=.575$, $p<.01$ ), suggesting that increases in body mass postpone the onset of heterosexual intercourse in females.

\subsection{Voice and sexual behavior}

For males, opposite-sex ratings of voice attractiveness were negatively correlated with reported age of first sexual intercourse and positively correlated with reported number of sex partners, EPC partners, and partners they had intercourse with who were involved in another relationship (see Table 1). The same pattern of results was obtained for females. As shown in Table 2, opposite-sex voice attractiveness ratings for females were negatively correlated with reported age of first sexual intercourse and positively correlated with reported number of sex partners, EPC partners, and partners they had intercourse with who were involved in another relationship. Tables 1 and 2 also show similar correlations for same-sex ratings of voice attractiveness and sexual behaviors.

\section{Discussion}

Our findings show that ratings of voice attractiveness can be used to predict significant variation in sexually dimorphic body configuration. Females with smaller WHRs and males with larger SHRs had voices that were consistently rated as more attractive. For females, WHR conveys information about hormonal profile, reproductive maturity, fecundity, and health (for a review, see Singh, 1993). For males, SHR correlates positively with betalipoproteins, hormones that are related to testosterone and muscle development (Evans, 1972), and higher androgen levels in males may contribute to the development of sex-related differences in skeletal morphology and muscle mass at puberty (Kasperk et al., 1997). Because the sex hormones that influence the emergence of sexually dimorphic configurations of SHR and WHR are the same as those that drive the emergence of sex differences in vocal 
structure during adolescence (Abitbol et al., 1999), there may be a fairly direct hormonal link between these features. Whereas male SHR was correlated with both opposite- and same-sex ratings of voice attractiveness, female WHR was only predicted by opposite-sex voice attractiveness ratings.

Some investigators contend that WHR is confounded with body mass, especially among females (e.g., Wetsman \& Marlowe, 1999). While our data show that WHR is related to voice attractiveness in females, there was no evidence for an association between BMI and voice attractiveness for either sex. Some findings show that height and weight can be estimated from voice samples (Krauss et al., 2002; Lass \& Colt, 1980; Lass \& Davis, 1976). But when it comes to ratings of voice attractiveness, our results show that height and weight, as scaled by BMI, are not related. Although Collins and Missing (2003) found that vocal attractiveness was negatively related to female "body size," our data suggest that the relationship between voice attractiveness and body features is driven by the variation in WHR, not BMI. Unlike WHR and SHR, the only significant correlation between BMI and any of the measures taken in our study was age of first sexual intercourse among females. As BMI for females increased, there was a corresponding increase in the reported age of first sexual intercourse. Therefore, it would appear that increases in BMI retard or delay the onset of heterosexual intercourse among females.

We also found associations between voice attractiveness ratings and different features of self-reported sexual behavior. Both males and females whose voices were rated as attractive had sex at an earlier age, had more sexual partners, more EPC partners, and more sexual partners that were involved in a relationship with another person. It is interesting that voice attractiveness ratings by members of the opposite sex were better predictors of sexual behavior than ratings by members of the same sex. Aside from Wilson (1984), who noted that lower voiced male opera singers were more inclined to have sexual affairs with fellow singers, our findings are the first to empirically implicate the existence of a relationship between voice and sexual behavior.

Individuals with attractive voices are perceived more favorably and as having more desirable personality characteristics (Zuckerman \& Driver, 1989). Furthermore, the higher the ratings of voice attractiveness, the more the speaker is judged to be similar to the rater and the more the rater would like to affiliate with the speaker (Miyake \& Zuckerman, 1993). This "vocal attractiveness stereotype" (Zuckerman \& Driver, 1989; Zuckerman, Hodgins, \& Miyake, 1990) may promote sexual opportunities. Although Zuckerman and Driver (1989) did not find an effect, Collins and Missing (2003) report a substantial correlation between ratings of voice attractiveness and of facial attractiveness in women. Therefore, since ratings of facial attractiveness predict semen quality in males (Soler et al., 2003) and longevity in both males and females (Henderson \& Anglin, 2003), voice attractiveness may be an indicator (albeit indirect) of other fitness-related features as well.

Our findings replicate those of Hughes and Gallup (2003) concerning the relationship between various measures of sexual behavior and body configuration. Reported age of first sex, number of sex partners, number of EPC partners, and number of sexual partners who were involved in another relationship were all significantly correlated with SHR in males and with WHR in females (see Tables 1 and 2). However, unlike fluctuating asymmetry (Hughes 
et al., 2002), the relationship between voice attractiveness and body configuration in females was influenced by the sex of the rater.

It is interesting that voice attractiveness was a better predictor of sexual behavior in females than WHR was. The best predictor of promiscuity (as measured by number of sexual partners) in males was SHR, whereas in females, it was voice attractiveness. As shown in Table 2, the correlations between opposite-sex ratings of voice attractiveness and sexual behavior in females were consistently higher than those found for WHR and sexual behavior. However, just the opposite was true for males (see Table 1). Among males, SHR was a better predictor of sexual behavior than voice was. For example, whereas opposite-sex voice attractiveness accounted for $13 \%$ of the variance in promiscuity among males, SHR accounted for $28 \%$ of the variance in male promiscuity. The same sex differences held for the relationship between voice and body configuration. Male SHR accounted for more variance $(25 \%)$ in opposite sex ratings of voice attractiveness than did female WHR (14\%).

Our findings suggest that during human evolutionary history, voice may have been an important parameter of mate choice, particularly at night, when vision was compromised (for details, see Hughes et al., 2002). Not only does voice map onto language as our principal mode of communication, but it appears that irrespective of content the mere sound of an individual's voice also provides important information about a host of biologically relevant features such as fluctuating asymmetry, body configuration, and sexual behavior.

\section{Acknowledgments}

The authors wish to thank R. Nathan Pipitone, Julie Johnson, Jennifer Rodden, Josianne Mondor, and Michael Frederick for help with data collection, and Marissa Harrison, Steven Platek, and Todd Shackelford for helpful comments on a previous draft of this paper.

\section{References}

Abitbol, J., Abitbol, P., \& Abitbol, B. (1999). Sex hormones and the female voice. Journal of Voice, 13, 424-446. Allport, G. W., \& Cantril, H. (1934). Judging personality from voice. Journal of Social Psychology, 5, $37-55$.

Beck, S., Ward-Hull, C., \& McClear, P. (1976). Variables related to women's somatic preferences of the male and female body. Journal of Personality and Social Psychology, 34, 1200-1210.

Collins, S. A., \& Missing, C. (2003). Vocal and visual attractiveness are related in women. Animal Behaviour, 65 , 997-1004.

Dijkstra, P., \& Buunk, B. P. (2001). Sex differences in the jealousy-evoking nature of a rival's body build. Evolution and Human Behavior, 22, 335-341.

Ekman, P., Friesen, W. V., \& Scherer, K. (1976). Body movements and voice pitch in deceptive interaction. Semiotica, 16, 23-27.

Ellis, D. S. (1967). Speech and social status in America. Social Forces, 45, 431-437.

Evans, R. B. (1972). Physical and biochemical characteristics of homosexual men. Journal of Consulting and Clinical Psychology, 39, 140-147.

Harms, L. S. (1963). Listener comprehension of speakers of three status groups. Language Speech, 4, $109-112$. 
Henderson, J. J. A., \& Anglin, J. M. (2003). Facial attractiveness predicts longevity. Evolution and Human Behavior, 24, 351-356.

Hughes, S. M., \& Gallup Jr., G. G. (2003). Sex differences in morphological predictors of sexual behavior: shoulder to hip and waist to hip ratios. Evolution and Human Behavior, 24, 173-178.

Hughes, S. M., Harrison, M. A., \& Gallup Jr., G. G. (2002). The sound of symmetry: voice as a marker of developmental instability. Evolution and Human Behavior, 23, 173-180.

Kasperk, C., Helmboldt, A., Borcsok, I., Heuthe, S., Cloos, O., Niethard, F., \& Ziegler, R. (1997). Skeletal sitedependent expression of the androgen receptor in human osteoblastic cell populations. Calcified Tissue, 61, $464-473$.

Krauss, R. M., Freyberg, R., \& Morsella, E. (2002). Inferring speakers' physical attributes from their voices. Journal of Experimental Social Psychology, 38, 618-625.

Lass, N. J., \& Colt, E. G. (1980). A comparative study of the effect of visual and auditory cues on speaker height and weight identification. Journal of Phonetics, 8, 277-285.

Lass, N. J., \& Davis, M. (1976). An investigation of speaker height and weight identification. Journal of the Acoustical Society of America, 60, 700-704.

Mikach, S. M., \& Bailey, M. (1999). What distinguishes women with unusually high numbers of sex partners? Evolution and Human Behavior, 20, 141-150.

Miyake, K., \& Zuckerman, M. (1993). Beyond personality impressions: effects of physical and vocal attractiveness on false consensus, social comparison, affiliation, and assumed and perceived similarity. Journal of Personality, 61, 411-437.

Singh, D. (1993). Adaptive significance of female physical attractiveness: role of waist-to-hip ratio. Journal of Personality and Social Psychology, 65, 293-307.

Soler, C., Núñez, M., Gutiérrez, R., Núñez, J., Medina, P., Sancho, M., Álvarez, J., \& Núñez, A. (2003). Facial attractiveness in men provides clues to semen quality. Evolution and Human Behavior, 24, 199-207.

Streeter, L. A., Krauss, R. M., Geller, V. J., Olson, C. T., \& Apple, W. (1977). Pitch changes during attempted deception. Journal of Personality and Social Psychology, 35, 345-350.

Tovée, M. J., Reinhart, S., Emery, J. L., \& Cornelissen, P. L. (1998). Optimum body-mass index and maximum sexual attractiveness. Lancet, 352, 548.

Wetsman, A., \& Marlowe, F. (1999). How universal are preferences for female waist-to-hip ratios? Evidence from the Hadza of Tanzania. Evolution and Human Behavior, 20, 219-228.

Wilson, G. D. (1984). The personality of opera singers. Personality and Individual Differences, 5, 195-201.

Zuckerman, M., \& Driver, R. (1989). What sounds beautiful is good: the vocal attractiveness stereotype. Journal of Nonverbal Behavior, 13, 67-82.

Zuckerman, M., Hodgins, H., \& Miyake, K. (1990). The vocal attractiveness stereotype: replication and elaboration. Journal of Nonverbal Behavior, 14, 97-112. 